\title{
Kristin Kleber, Reinhard Pirngruber (eds.). Silver, Money and Credit. A tribute to Robartus J. van der Spek On the Occasion of his 65th Birthday
}

\section{Astrid Nunn}

\section{(2) OpenEdition}

Journals

Édition électronique

URL : http://journals.openedition.org/abstractairanica/45697

DOI : 10.4000/abstractairanica.45697

ISBN : 1961-960X

ISSN : 1961-960X

Éditeur :

CNRS (UMR 7528 Mondes iraniens et indiens), Éditions de l'IFRI

\section{Référence électronique}

Astrid Nunn, « Kristin Kleber, Reinhard Pirngruber (eds.). Silver, Money and Credit. A tribute to Robartus J. van der Spek On the Occasion of his 65th Birthday », Abstracta Iranica [En ligne], Volume 37-38-39 | 2018, document 64, mis en ligne le 30 décembre 2018, consulté le 26 septembre 2020. URL : http:// journals.openedition.org/abstractairanica/45697 ; DOI : https://doi.org/10.4000/abstractairanica. 45697

Ce document a été généré automatiquement le 26 septembre 2020.

Tous droits réservés 


\title{
Kristin Kleber, Reinhard Pirngruber (eds.). Silver, Money and Credit. A tribute to Robartus J. van der Spek On the Occasion of his 65th Birthday
}

\author{
Astrid Nunn
}

\section{RÉFÉRENCE}

Kristin Kleber, Reinhard Pirngruber (eds.). Silver, Money and Credit. A tribute to Robartus J. van der Spek On the Occasion of his 65th Birthday. Louvain: Peeters Publisher, 2016, $\mathrm{xxix}+348 \mathrm{p} .,(\mathrm{PIHANS}, 128$ )

1 Ce volume est édité en l'honneur de Robartus J. van der Spek, spécialiste des questions monétaires au Proche-Orient dans la seconde moitié $d u I^{\text {er }}$ millénaire av. J.-C. Les éditeurs se sont faits eux-mêmes un nom dans le domaine de l'économie. Les nombreux articles offrent un éventail largement ouvert sur tant la chronologie (à commencer par Theo Krispijn sur les documents cunéiformes d'Uruk au III ${ }^{e ̀ m e}$ millénaire) que la géographie qui englobe la Mésopotamie, la Chine, l'Empire perse achéménide, le Levant et la Grèce.

Nous ne reprendrons ici que les contributions qui concernent la période achéménide :

3 - Caroline Waerzeggers, "The Silver has gone... Temple Theft and a Divided Community in Achaemenid Babylonia" (p.73-85)

4 L'A. publie un document judiciaire cunéiforme qui date de la première année de Darius et provient de Sippar. Il relate de la disparition de trois précieuses vaisselles en argent du trésor de la ziggurrat. L'A. évoque l'année agitée de 522 - 521, pendant laquelle le passage du règne de Nabuchodonozor IV à l'accession de Darius Ier est accompagné de violents incidents opposant deux parties adverses. Le vol aurait eu lieu dans ce contexte conflictuel. 
5 - Reinhard Pirngruber, "The Value of Silver: Wages as Guides to the Standard of Living in First Millennium BC Babylonia" (p.107-118)

6 L'A. a abandonné le modèle traditionnel d'une économie babylonienne surtout distributive. La population urbaine aurait en grandissant stimulé le développement du marché, des échanges basés sur la monnaie et de la spécialisation. L'A. essaie d'évaluer le niveau de vie des habitants de Babylone au VI ${ }^{\text {ème }}$ siècle.

7 Dans ce but, il calcule leur pouvoir d'achat par le biais des revenus, des besoins quotidiens et des dépenses. Il arrive à la conclusion qu'au $6^{\text {ème }}$ siècle les habitants de Babylone disposaient en moyenne de plus que du minimum nécessaire et étaient relativement aisés. Cette situation se détériorera à partir du V ème $s$. av. J.-C et le niveau de vie sera encore inférieur aux époques séleucide et parthe du III ${ }^{\text {ème }}$ et II ${ }^{\text {ème }}$ siècles av. J.-C.

8 - Wouter F.M. Henkelman and Margaretha L. Folmer, "Your Tally is Full! On Wooden Credit Records in and after the Achaemenid Empire" (p.133-239)

960 documents, censés provenir d'Afghanistan, sont apparus sur le marché vers 2000. Il s'agit de bandes soit en cuir, soit en bois, écrites et pour certaines dotées d'incisions sur le bord. La plupart sont écrites en araméen achéménide et datent du $4{ }^{\text {ème }}$ siècle. Les A. livrent une analyse détaillée de ce que l'on appelle maintenant the Aramaic Documents from Ancient Bactria. Ils débutent avec un aperçu sur ce genre de document incisé qui existe depuis le néolithique. Ils examinent ensuite longuement le système de notation qui rassemble quatre sortes de marques dans un système décimal.

10 Les comptes semblent noter les dépenses. Mais la nature de ce qui est acheté n'est jamais révélée, il pourrait néanmoins s'agir d'argent. La dernière question concerne la familiarité de l'administration centrale achéménide avec ce genre de documents administratifs. La langue et le système de notation étant compatibles avec celui de Persépolis, les A. n'excluent pas leur emploi dans un contexte plus large que celui de la Bactriane.

11 - Mark Tamerus, "Elusive Silver in the Achaemenid Heartland: Thoughts on the Presence and Use of Silver According to the Persepolis Fortification and Treasure Archives" (p.241-294)

L'A. examine la quantité d'argent métal en circulation dans l'économie de l'Empire achéménide. La source principale, ce sont les Tablettes des Fortifications (Darius années 13-28, 509-493 av. J.-C.) et celles de la Trésorerie (Darius 29-Arataxerxès Ier 7, 492-458 av. J.-C.) de Persépolis. Les paiements s'effectuent aussi en argent métal dans les Tablettes du Trésor, à l'inverse de ce qu'indiquent les tablettes des Fortifications. Même les références à ce métal y sont rares. Les monnaies en argent ne jouèrent aucun rôle important. Ceci ne signifie pas toutefois que l'usage de la monnaie en argent était inconnu avant la fin du règne de Darius. Certaines transactions de laine se faisaient avec de l'argent, ou encore de temps à autre, les ouvriers recevaient des dons d'argent. Tout ceci aboutit à la question de la thésaurisation du métal argent. Considéré comme un métal précieux, à valeur mesurée et même parfois sous forme de barre poinçonnée, l'argent pouvait dorénavant être accumulé. 


\section{AUTEURS}

\section{ASTRID NUNN}

Université de Munich 